\title{
ANALISIS PERENCANAAN DAN PENGENDALIAN PERSEDIAN BAHAN BAKU BAJU KAOS DENGAN METODE ECONOMIC ORDER QUANTITY (EOQ) PADA JIMS KAOS TAHUN 2017
}

\author{
Komang Rosa Rusdiana ${ }^{1}$,lyus Akhmad Haris ${ }^{2}$ \\ Jurusan Pendidikan Ekonomi \\ Universitas Pendidikan Ganesha \\ Singaraja, Indonesia \\ e-mail: rosarusdiana9@gmail.com ${ }^{1}$, iyus.haris@gmail.com²
}

\begin{abstract}
Abstrak
Penelitian ini bertujuan untuk mengetahui perencanaan dan pengendalian persediaan bahan baku baju kaos pada perusahaan Jims Kaos tahun 2017 serta perencanaan dan pengendalian persediaan bahan baku baju kaos dengan metode Economic Order Quantity (EOQ) pada perusahaan Jims Kaos tahun 2017.Jenis penelitian ini merupakan penelitian deskriptif dengan pendekatan kuantitatif.Data dikumpulkan dengan metode wawancara dan dokumenasi. Analisis data dalam penelitian ini menggunakan metodeEconomic Order Quantity (EOQ). Hasil penelitian menunjukkan bahwa rencana penjualan sebesar 38.803 baju, rencana produksi sebesar 36.314 baju, kebutuhan bahan baku katun combed sebesar $54.471 \mathrm{~m}$ katun rib sebesar $2.724 \mathrm{~m}$ benang jahit sebesar $65.365 .200 \mathrm{~m}$ benang obras sebesar $43.576 .800 \mathrm{~m}$, pembelian bahan baku katun combed sebesar $51.378 \mathrm{~m}$ katun rib sebesar $2.237 \mathrm{~m}$ benang jahit sebesar $66.590 .190 \mathrm{~m}$ benang oras sebesar $44.373 .376,9 \mathrm{~m}$, persediaan minimum bahan baku katun combed sebesar $3.605 \mathrm{~m}$ katun rib sebesar $53,2 \mathrm{~m}$ benang jahit sebesar 1.270 .990 mbenang obras sebesar $847,326,9 \mathrm{~m}$, reorder point bahan baku adalah 14 hari, persediaan maksimum bahan baku katun combed sebesar 4.292,3m katun rib sebesar $869,1 \mathrm{~m}$ benang jahit sebesar $1.303 .792 \mathrm{~m}$ benang obras sebesar 894.800,2m,Economic Order Quantity (EOQ) bahan baku katun combed sebesar $687,3 \mathrm{~m}$ katun rib sebesar $815,9 \mathrm{~m}$ benang jahit sebesar $32.805,6 \mathrm{~m}$ benang obras sebesar $47.473,3 \mathrm{~m}$.
\end{abstract}

Kata kunci: perencanaan, pengendalian, Economic Order Quantity (EOQ)

\begin{abstract}
This research was aimed to identify planning and controlling stock of t-shirt raw material at company Jims Kaos in years 2017, as well as planning and controlling the supplyof row materials t-shirt with Economic Order Quantity (EOQ)method in te company Jims Kaos in years 2017. This type of research is descriptive research with quantitative approach. Data were collected by interview and documentation method. Data analysis in this study using economic order quantity method. Research results show that the sales plan of 38.803 clothes, production plan of 36.314 clothes, the need for combed catton raw material of $54.471 \mathrm{~m}$ catton rib of $2.724 \mathrm{~m}$ sewing thread of $65.365 .200 \mathrm{~m}$ obras yarn of $43.576 .800 \mathrm{~m}$, purchase of combed catton raw material of $51.378 \mathrm{~m}$ catton rib of $2.237 \mathrm{~m}$ sewing thread of $66.590 .190 \mathrm{~m}$ obras yarn of 44.373.376,9m, minimum supplies of combed catton raw material of $3.605 \mathrm{~m}$ catton rib of $53,2 \mathrm{~m}$ sewing thread of $1.270 .990 \mathrm{~m}$ obras yarn of $847,326,9 \mathrm{~m}$, the raw material reorder points is 14 days, maximum inventory of combed catton raw materials of $4.292,3 \mathrm{~m}$ catton rib of $869,1 \mathrm{~m}$ sewing thread of 1.303 .792 obras yarn of $894.800,2 \mathrm{~m}$, Economic Order Quantity (EOQ) combed catton raw material of $687,3 \mathrm{~m}$ catton rib of $815,9 \mathrm{~m}$ sewing thread of $32.805,6 \mathrm{~m}$ obras yarn of $47.473,3 \mathrm{~m}$
\end{abstract}

Keywords:planning, control, Economic Order Quantity (EOQ) 


\section{PENDAHULUAN}

Perusahaan merupakan suatu lembaga usaha yang dikelola ataupun dijalankan perorangan atau secara bersama-sama bertujuan untuk memperoleh laba atau keuntungan yang maksimal. Pada dasarnya semua perusahaan melakukan perencanaan dan pengendalian bahan dengan tujuan mengefesienkan biaya dan memaksimalkan laba dalam waktu tertentu. Jumlah atau tingkat persediaan yang dibutuhkan oleh perusahaan berbeda-beda tergantung dari volume produksinya, jenis pabrik, dan prosesnya (Assauri, 2004). Untuk kelancaran proses produksi bagian produksi harus mengetahui persediaan yang tersedia karena jumlah persediaan akan menentukan atau mempengaruhi kelancaran proses produksi.

Secara umum perencanaan dan pengendalian persediaan bahan baku mencakup seluruh kegiatan mulai dari penentuan jumlah dan jenis bahan baku yang dibutuhkan, pencarian sumber atau tempat memperolehnya, cara pembeliannya, dan pengangkutannya ke tempat produksi (Pardede, 2005:411). Perencanaan bahan baku merupakan salah satu faktor yang menjamin kelancaran proses produksi, hal tersebut dimaksudkan untuk memenuhi kebutuhan bahan baku dalam proses produksi pada waktu yang akan datang.

Menurut Hansen (2011:422)

menyatakan "perencanaan adalah pandangan ke depan untuk melihat tindakan apa yang seharusnya dilakukan agar dapat mewujudkan tujuan-tujuan tertentu", sedangkan menurut Terry \& Leslie (2008:43) menyatakan "Perencanaan adalah proses memutuskan tujuan-tujuan apa yang akan dikejar selama suatu jangka waktu yang akan datang dan apa yang akan dikeluarkan agar tujuan-tujuan tercapai". Berdasarkan pengertian para ahli diatas dapat disimpulkan bahwa perencanaan merupakan pandangan kedepan untuk melihat tindakan apa yang seharusnya dilakukan dan proses memutuskan tujuantujuan agar apa yang akan dikejar selama jangka waktu tertentu dan dapat tercapai.
Menurut Earl P. Strong (2003:241) menyatakan "Pengendalian adalah proses pengaturan berbagai faktor dalam suatu perusahaan, agar pelaksaan sesuai dengan ketepatan-ketepatan dalam rencana". Menurut Indrajit \& Djokopranoto (2003) Pengendalian persediaan merupakan kegiatan yang berhubungan dengan perencanaan, pelaksanaan, dan pengawasan penentuan kebutuhan material sebagaian rupa sehingga disatu pihak kebutuhan operasi dapat dipenuhi pada waktunya dan dilain pihak investasi persediaan material dapat ditekan secara optimal. Tujuan perusahaan menerapkan pengendalian persediaan menurut Handoko (2000:359) yaitu Mengusahakan agar apa yang telah direncanakan bisa terjadi menjadi kenyataan, mengusahakan agar pelaksanaan pekerjaan sesuai dengan instruksi yang telah dikeluarkan, mengetahui kelemahan-kelemahan serta kesulitan-kesulitan yang dihadapi dalam pelaksanaan rencana. Dari keterengan di atas dapat disimpulkan bahwa tujuan pengendalian persediaan adalah untuk menjamin terdapatnya persediaan pada tingkat optimal agar produksi dapat berjalan dengan lancar dengan biaya persediaan yang minimal.

Perancanaan yang efektif harus didasarkan atas fakta-fakta dan informasi yang mendukung, bukan atas dasar emosi maupun keinginan semata.sahaan pabrik yang menggunakannya. Menurut Slamet (2009:27) "persediaan bahan baku adalah persediaan bahan mentah yang akan diproses dalam proses produksi, yang mana barang-barang tersebut dapat diperoleh dari sumber-sumber alam ataupun dibeli dari supplier atau perusahaan dan menghasilkan bahan baku bagi perusahaan pabrik yang menggunakannya". Pentingnya kegiatan perencanaan dan pengendalian persediaan bahan baku untuk mengatur pembelian tentang pelaksanaan pengadaan bahan baku yang diperlukan sesuai dengan jumlah yang dibutuhkan serta dengan biaya yang minimal, yang meliputi masalah pembelian bahan, menyimpan, dan memelihara bahan, mengatur pengeluaran bahan saat bahan dibutuhkan dan juga mempertahankan 
persediaan dengan jumlah yang optimal. Menurut Freddy Rangkudi (2000) tujuan dari adanya persediaan yaitu menghilangkan resiko keterlambatan datangnya barang atau bahan-bahan yang dibutuhkan oleh perusahaan, menghilangkan dari material yang dipesan berkualitas tidak baik sehingga harus dikembalikan, mengantisipasi bahanbahan yang dihasilkan secara musiman sehingga dapat digunakan bila bahan itu tidak ada dalam pasaran, mempertahankan stabilitas operasi perusahaan atau menjamin kelancaran arus produksi, mencapai penggunaan mesin yang optimal.

Penentuan besarnya persediaan bahan baku merupakan masalah yang penting bagi perusahaan, karena jika terjadi kesalahan dalam menentukan besarnya investasi (modal yang tertanam) dalam persediaan maka akan menekan keuntungan perusahaan. Apabila persediaan bahan baku terlalu besar dibandingkan kebutuhan perusahaan akan menambah biaya pemeliharaan dan kemungkinan mengalami penyusutan serta kualitas yang tidak dapat di pertahankan sehingga mengurangi laba atau keuntungan yang di dapat perusahaan. Sebaliknya apabila persediaan bahan baku terlalu kecil dalam perusahaan akan mempengaruhi kemacetan dalam produksi, sehingga perusahaan mengalami kerugiaan akibat tidak dapat melayani pelanggan.

$$
\text { Setiap perusahaan sudah }
$$

seharusnya melakukan pengawasan terhadap persediaan, agar lebih efisiensi dalam penggunaan uang untuk persediaan, namun pengawasan terhadap persediaan bukan berarti dapat menyelesaikan semua resiko yang muncul karena persediaan yang besar atau kecil, akan tetapi dapat mengurangi resiko agar menjadi sekecil mungkin.

Menurut Kasmir (2010) terdapat dua metode pengendaliaan persediaan yaitu metode Just In Time (JIT) dan metode Economic Order Quantity (EOQ). Metode Just In Time (JIT) adalah metode penentuan jumlah sediaan yang diperoleh dan dimaskukkan dalam produksi secara tepat pada saat dibutuhkan perusahaan, sedangkan metode Economic Order Quantity (EOQ) merupakan jumlah pembelian bahan mentah pada setiap kali pesan dengan biaya yang paling rendah. Tindakan yang pertama kali dilakukan dalam mengelola persediaan adalah melakukan pembelian barang dengan biaya yang paling optimal. Menurut Witjaksono (2006:170), "Economic Order Quantity (EOQ) adalah kuantitas pemesanan yang terbaik atau yang paling ekonomis yang meminimalkan total biaya per periode". Untuk melakukan hal itu diperlukan metode Economic Order Quantity (EOQ). Metode Economic Order Quantity (EOQ) adalah suatu model yang menyangkut tentang pengadaan atau persediaan bahan baku pada suatu perusahaan. Dengan memperhitungkan jumlah kuantitas persediaan yang paling ekonomis maka perusahaan akan dapat merencanakan dan mengendalikan persediaan bahan baku yang ada.

Dari observasi awal yang dilakukan, Jims Kaos merupakan salah satu perusahaan yang bergerak di bidang garment yaitu pembuatan baju kaos.

Perusahaan garment Jims kaos ini memasarkan produksinya masih di wilayah Buleleng saja karena perusahaan garment Jims Kaos masih relatif muda berdirinya yaitu baru 3 tahun. Selama 3 tahun berdirinya perusahaan garment ini banyak masalah yang dihadapi, salah satu nya yaitu dalam persediaan bahan baku. Jims Kaos sering mengalami kekurangan maupun kelebihan bahan baku dari tahun 2014-2016.

Perusahaan

mengalami

kekurangan persediaan bahan baku karena terjadi kelebihan pesanan akan baju kaos sedangkan persediaan bahan baku yang tersedia habis, untuk memeroleh bahan baku Jims Kaos harus memesan dan menunggu kiriman dari Denpasar. Hal ini menyebabkan keberlangsungan proses produksi menjadi terganggu. Apabila terjadinya kelebihan persediaan bahan baku secara tidak langsung akan mempengaruhi penerimaan laba yang diterima Jims Kaos.

Sedangkan di lain waktu Jims Kaos mengalami kelebihan persediaan bahan baku yang disebabkan ketakutan 
akan kehabisan bahan baku yang dibutuhkan untuk proses produksi, sehingga Jims Kaos membeli bahan baku dengan jumlah banyak. Jika dilihat dari sudut pandang Jims Kaos hal ini tidak menjadi permasalahan karena bahan baku yang berlebihan dapat digunakan untuk prosees produksi selanjutnya. Sedangkan jika dilihat dari segi ekonomi, hal ini merupakan suatu permasalahan karena banyak nya dana yang keluarkan tertanam untuk pembelian persediaan bahan baku yang akan menyebabkan biaya akan penyimpanan yang berlebihan.

Berdasarkan hasil observasi awal yang dilakukan pada Jims Kaos, dapat disimpulkan bahwa persediaan bahan baku pada Jims Kaos mengalami kelebihan maupun kekurangan akan persediaan bahan baku. Dari latar belakang di atas, maka peneliti berkeinginan untuk melakukaan penelitian terhadap persediaan bahan baku pada Jims Kaos yang bejudul "Analisis Perencanaan dan Pengendalian Persediaan Bahan Baku Baju Kaos dengan Metode Economic Order Quantity (EOQ) Pada Jims Kaos Tahun 2017".

Berdasarkan latar belakang di atas, maka dapat dirumuskan masalah sebagai berikut.Pertama bagaimana perencanaan dan pengendalian persediaan bahan baku baju kaos pada Perusahaan Jims Kaos Tahun 2017, kedua bagaimana perencanaan dan pengendalian persediaan bahan baku baju kaos dengan Metode Economic Order Quantity (EOQ) pada Perusahaan Jims Kaos Tahun 2017.

Tujuan dari penelitian ini yaitu mengetahui hal-hal sebagai berikut. Pertama perencanaan dan pengendalian persediaan bahan baku baju kaos pada Perusahaan Jims Kaos Tahun 2017. Kedua perencanaan dan pengendalian persediaan bahan baku baju kaos dengan Metode Economic Order Quantity (EOQ) pada Perusahaan Jims Kaos Tahun 2017. Jenis penelitian ini merupakan penelitian diskriptif dengan pendekatan kuantitatif dengan fokus penelitian pada perencanaan dan pengendalian persediaan bahan baku baju kaos tahun 2017.
Volume 10 No. 1 Tahun 2018

\section{METODE}

Data yang dicari berupa data jenis bahan baku yang digunakan untuk membuat baju kaos dan data stock persediaan bahan baku dari tahun 20142016. Data yang dihasilkan berupa data yang terkait dengan perencanaan dan pengendalian bahan baku dengan menggunakan Economic Order Quantity (EOQ).Penelitian ini dilakukan pada perusahaan garment Jim's Kaos yang beralamat di Jalan Pemuda Banjar Dinas Bubunan Banjar Kelodan, Kecamatan Seririt, Kabupaten Buleleng.

Subyek penelitian ini adalah garment pembuatan baju kaos Jims Kaos sedangkan obyek dalam penelitian ini adalah persediaan bahan baku baju kaos pada Jims Kaos dengan fokus pada perencanaan dan pengendalian persediaan bahan baku baju kaos pada Jims Kaos tahun 2017.Bedasarkan sifatnya, data yang digunakan dalam penelitian ini adalah sebegai berikut.Data kualitatif dalam penelitian ini adalah data jenis bahan baku yang digunakan untuk membuat baju kaos. Data kuantitatif dalam penelitian ini adalah data stock persediaan bahan baku dari tahun 2014-2016.

Berdasarkan sumbernya, data yang digunakan dalam penelitian ini adalah sebagai berikut. Data primer dalam penelitian ini diperoleh secara langsung melalui wawancara dengan pemilik atau pengelola dan karyawan garment Jims Kaos. Data primer dalam penelitian ini adalah jenis bahan baku yang digunakan dalam pembuatan baju kaos.Data sekunder dalam penelitian ini diperoleh dalam bentuk dokumen-dokumen atau arsip-arsip yang dimiliki oleh garment Jims Kaos. Data sekunder dalam penelitian ini adalah data stock persediaan bahan baku dari tahun 2014-2016.

Metode yang digunakan dalam pengumpulan data pada penelitian ini adalah sebagai berikut.Metode wawancara sebagai alat utama yang dipergunakan dalam pengumpulan data. Teknik wawancara ini ditujukkan kepada pihak-pihak yang berwenang memberikan ijin penelitian dan mengeluarkan data. Wawancara dilakukkan dengan memberikan pertanyaan yang ditujukkan 
p-ISSN : 2599-1418

e-ISSN : 2599-1426

kepada pemilik atau pengelola garment Jims Kaos, Adapun pertanyaannya yaitu untuk mengetahui jenis bahan baku yang digunakan dalam pembuatan baju kaos. Dokumentasi adalah teknik yang dilakukan dengan memanfaatkan dokumendokumen tertulis.

Dalam penelitian ini dokumendokumen yang digunakan adalah data stock persediaan bahan baku dari tahun 2014-2016. Dalam penelitian ini, data akan di analisis dengan menggunakan analisa sebagai berikut. menyusun rencana penjualan, menyusun rencana produksi, menyusun rencana kebutuhan bahan baku, menyusun rencana pembelian bahan baku, menentukan persediaan minimum (Safety Stock), menentukan Economic Order Quantity (EOQ)Menurut Sumayang (2003:208) menjabarkan rumus $\mathrm{EOQ}$ sebagai berikut.

$Q=\sqrt{\frac{2 S L}{i C}}$

Keterangan:

$\mathrm{Q}=$ jumlah kuantitas pesanan yang paling ekonomis (EOQ)

$\mathrm{D}=$ jumlah kebutuhan barang yang dibeli selama setahun

$S$ = biaya setiap kali pemesanan barang

$\mathrm{C}=$ harga barang per unit

$\mathrm{i}=$ persentase terhadap nilai persediaan

per tahun
Jurnal Pendidikan Ekonomi Undiksha

Volume 10 No. 1 Tahun 2018

Menentukan reorder point, menentukan persediaan maksimum

\section{HASIL DAN PEMBAHASAN \\ Hasil}

Perencanaan dan pengendalian yang dibuat oleh Jims Kaos dalam rangka untuk merencanakan dan mengendalikan persediaan bahan baku pada tahun 2017 dimulai dari menyusun rencana penjualan, menyusun rencana produksi, menyusun rencana kebutuhan bahan baku, menyusun rencana pembelian bahan baku, menentukan persediaan minimum (safety stock), menentukan reorder point, dan menentukan persediaan maksimum.

Menyusun rencana penjualan baju kaos pada Jims Kaos untuk tahun 2017 dapat dilakukan dengan menggunakan bantuan dari data penjualan baju kaos tahun sebelumnya. Disini peneliti menggunakan bantuan data penjualan baju kaos dari tiga tahun sebelumnya dari tahun 2014 sampai dengan 2016, sedangkan metode yangdigunakan untuk menyusun rencana penjualan adalah metode least square. Metode last square yaitu untuk meramalkan penjualan pada masa yang akan datang dengan menggunakan data penjualan sebelumnya. Data penjualan baju kaos pada Jims Kaos dari tahun 2014 sampai dengan tahun 2016 nampak pada tabel

Tabel 1. Data Penjualan Baju Kaos pada Jims Kaos dari tahun 2014 sampai dengan 2016 dalam Satuan

\begin{tabular}{cccc}
\hline Bulan & 2014 & 2015 & 2016 \\
\hline Januari & 2.880 & 2.784 & 2.952 \\
Februari & 3.120 & 3.168 & 3.156 \\
Maret & 3.312 & 3.228 & 3.336 \\
April & 3.024 & 3.048 & 3.264 \\
Mei & 3.060 & 3.072 & 3.198 \\
Juni & 2.568 & 2.988 & 3.102 \\
Juli & 3.156 & 3.096 & 3.174 \\
Agustus & 3.192 & 3.144 & 3.258 \\
September & 2.808 & 2.958 & 3.090 \\
Oktober & 2.832 & 2.994 & 3.138 \\
Nopember & 2.952 & 3.018 & 3.162 \\
Desember & 2988 & 3.006 & 3.246 \\
\hline Jumlah & 35.892 & 36.564 & 38.076 \\
\hline
\end{tabular}


p-ISSN : 2599-1418

e-ISSN : 2599-1426

Berdasarkan data penjualan baju kaos pada tabel 1, maka garment pembuatan baju kaos pada Jims Kaos
Jurnal Pendidikan Ekonomi Undiksha

Volume 10 No. 1 Tahun 2018

dapat memperkirakan jumlah penjualan baju kaos tahun 2017 seperti nampak pada tabel

Tabel 2. Data Rencana Penjualan Baju Kaos pada Jims Kaos tahun 2017 dalam Satuan

\begin{tabular}{cc}
\hline Bulan & Jumlah \\
\hline Januari & 3.196 \\
Februari & 3.203 \\
Maret & 3.210 \\
April & 3.217 \\
Mei & 3.223 \\
Juni & 3.230 \\
Juli & 3.237 \\
Agustus & 3.244 \\
September & 3.251 \\
Oktober & 3.257 \\
Nopember & 3.264 \\
Desember & 3.271 \\
\hline Jumlah & 38.803 \\
\hline
\end{tabular}

Rencana produksi baju kaos

pada Jims Kaos tahun 2017 adalah sebagai berikut.

Rencana penjualan baju kaos pada Jims Kaos selama tahun 2017 adalah38.803 baju.Jadi penjualan baju kaos pada Jims Kaos selama sebulan adalah 38.803 baju : 12 bulan $=3.234$ baju

Hari kerja dalam sebulan adalah 30 hari Jadi kebutuhan per hari adalah 3.34 baju : 30 hari $=108$ baju. Jims Kaos menentukan persediaan akhir baju kaos untuk tahun 2017 sebesar 7 hari $\times 108$ baju $=756$ baju. Persediaan awal baju kaos tahun 2017 dapat diketahui dari ersediaan akhir baju kaos tahun 2016.Maka dapat dibuat perhitungan sebagai berikut. Rencana penjualan baju kaostahun 2017 sebesar 38.803 ditambah rencana persediaan akhir baju kaos tahun 2017 sebesar 756 mendapatkan hasil kebutuhan produk baju kaos tahun 2017 sebesar 39.559 dikurangi persediaan awal baju kaos tahun 2017 sebesar 3.245 mendapatkan hasil rencana produksi baju kaos tahun 2017 sebesar 36.314. Jadi rencana produksi baju kaos pada Jims Kaos selama tahun 2017 adalah sebesar 36.314 baju. Setelah mengetahui rencana produksi baju kaos pada Jims Kaos tahun 2017, maka dapat dibuat rencana kebutuhan bahan baku yang diperlukan Jims Kaos untuk tahun 2017.

Rincian rencana kebutuhan bahan baku baju kaos pada Jims Kaos tahun 2017 nampak pada tabel 3.

Tabel 3 Rincian Rencana Kebutuhan Bahan Baku Baju Kaos pada Jims Kaos tahun 2017

\begin{tabular}{llrc}
\hline No. & \multicolumn{1}{c}{ Jenis Bahan } & R. Produksi X Standar P.B.B & R.K. Bhn Baku \\
\hline 1 & Katun Combed & 36.314 baju X $1,5 \mathrm{~m}$ & $54.471 \mathrm{~m}$ \\
2 & Katun Rib & 36.314 baju X $0,075 \mathrm{~m}$ & $2.724 \mathrm{~m}$ \\
3 & Benang Jahit & 36.314 baju X $1.800 \mathrm{~m}$ & $65.365 .200 \mathrm{~m}$ \\
4 & Benang Obras & 36.314 baju X $1.200 \mathrm{~m}$ & $43.576 .800 \mathrm{~m}$ \\
\hline
\end{tabular}

Setelah mengetahui rencana pembelian masing-masing bahan baku kebutuhan masing-masing bahan baku selama tahun 2017 adalah sebagai selama tahun 2017, maka dapat dibuat berikut. Rencana kebutuhan bahan katun rencana pembelian masing-masing bahan combed selama tahun 2017 adalah baku untuk tahun 2017. Rencana sebesar $54.471 \mathrm{~m}$. Jadi kebutuhan bahan 
katun combed selama sebulan adalah $54.471 \mathrm{~m}$ : 12 bulan $=4.539 \mathrm{~m}$. Jadi kebutuhan bahan katun combed per hari adalah. $4.539 \mathrm{~m}: 30$ hari $=151 \mathrm{~m}$. Jims Kaos menentukan persediaan akhir bahan katun combad sebesar 7 hari $\times 151 \mathrm{~m}=$ $1.057 \mathrm{~m}$.

Persediaan awal bahan katun combad tahun 2017 dapat diketahui dari persediaan akhir bahan katun combed tahun 2016. Maka dapat di buat perhitungan sebagai berikut sebesar 54.471 ditambah rencana persediaan akhir bahan katun combed tahun 2017 sebesar 1.057 memperoleh hasil Bahan katun combed yang tersedia tahun 2017 sebesar 55.528 dikurangi persediaan awal bahan katun combad tahun 2017 sebesar 4.150 memperoleh hasil Pembelian bahan katun combed 2017 sebesr 51.578. Jadi pembelian bahan baku katun combed selama tahun 2017 adalah sebesar $51.378 \mathrm{~m}$. Rencana kebutuhan bahan katun rib selama tahun 2017 adalah sebesar $2.724 \mathrm{~m}$ Jadi kebutuhan bahan katun ribselama sebulan adalah $2.724 \mathrm{~m}$ : 12 bulan $=227 \mathrm{~m}$. Jadi kebutuhan bahan katun ribper hari adalah $227 \mathrm{~m}$ : 30 hari $=$ 7,6m. Jims Kaos menentukan persediaan akhir bahan katun rib sebesar 7 hari $x$ $7,6 m=53,2$.

Persediaan awal bahan katun rib tahun 2017 dapat diketahui dari persediaan akhir bahan katun rib tahun 2016. Maka dapat di buat perhitungan sebagai berikut. Kebutuhan bahan katun rib selama tahun 2017 sebesar2.724 ditambah rencana persediaan akhir bahan katun rib tahun 2017 sebesar 53,2 memperoleh hasil bahan katun rib yang tersedia tahun 2017 sebesar 2.777,3 dikurangi persediaan awal bahan katun combad tahun 2017 sebesar 540 memperoleh hasil pembelian bahan katun rib 2017 sebesar 2.237,2. Jadi pembelian bahan baku katun rib selama tahun 2017 adalah sebesar $2.237,2 \mathrm{~m}$. Rencana kebutuhan bahan benang jahit selama tahun 2017 adalah sebesar 65.365.200m Jadi kebutuhan bahan benang jahit selama sebulan adalah $65.365 .200 \mathrm{~m}: 12$ bulan =
$544.710 \mathrm{~m}$. Jadi kebutuhan bahan benang jahit per hari adalah $5.447 .100 \mathrm{~m}: 30$ hari $=181.570 \mathrm{~m}$ Jims Kaos menentukan persediaan akhir bahan benang sebesar 7 hari $x 181.570 \mathrm{~m}=1.270 .990 \mathrm{~m}$

Persediaan awal bahan benang jahit tahun 2017 dapat diketahui dari persediaan akhir bahan benangjahit tahun 2016. Maka dapat di buat perhitungan sebagai berikut. Kebutuhan bahan benang jahit selama tahun 2017 sebesar 65.365.200 ditambah rencana persediaan akhir bahan benang jahit tahun 2017 sebesar 1.270.990 memperoleh hasil bahan benang jahit yang tersedia tahun 2017 sebesar 66.636.190 dikurangi persediaan awal bahan benang jahit tahun 2017 sebesar 46.000 memperoleh hasil pembelian bahan benang jahit 2017 sebesar 66.590.190. Jadi pembelian bahan baku benang jahitselama tahun 2017 adalah sebesar 66.590.190m. Rencana kebutuhan bahan benang obras selama tahun 2017 adalah sebesar 43.576.800m Jadi kebutuhan bahan benang obras selama sebulan adalah $43.576 .800 \mathrm{~m}: 12$ bulan $=3.631 .400 \mathrm{~m}$ Jadi kebutuhan bahan benang obras per hari adalah $3.631 .400 \mathrm{~m}: 30$ hari $=$ $121.046,7 \mathrm{~m}$ Jims Kaos menentukan persediaan akhir bahan benang obras sebesar 7 hari $x 121.046,7 \mathrm{~m}=$ $847.326,9 \mathrm{~m}$. Persediaan awal bahan benang obras tahun 2017 dapat diketahui dari persediaan akhir bahan benang obras tahun 2016.Maka dapat di buat perhitungan sebagai berikut. Kebutuhan bahan benang obras selama tahun 2017 sebesar 43.576.800 ditambah rencana persediaan akhir bahan benang obras tahun 2017 sebesar 847.326,9 memperoleh hasil bahan benang obras yang tersedia tahun 2017 sebesar 44.424.126,9 dikurangi persediaan awal bahan benang obras tahun 2017 sebesar 50.750 memperoleh hasil pembelian bahan benang obras 2017 sebesar 44.373.376,9m. Jadi pembelian bahan baku benang obras selama tahun 2017 adalah sebesar 44.373.376,9m. Rincian persediaan minimum baju kaos pada Jims Kaos tahun 2017 nampak pada tabel 4 . 
Tabel 4. Rincian persediaan Minimum Bahan Baku Baju Kaos pada Jims Kaos Tahun 2017

\begin{tabular}{clcc}
\hline \multirow{2}{*}{ No. } & \multirow{2}{*}{ Jenis Bahan } & Lead Timex Kebutuhan Bahan per Hari & Safety Stock \\
\hline 1 & Katun Combed & 7 hari $\times 515 \mathrm{~m}$ & $3.605 \mathrm{~m}$ \\
2 & Katun Rib & 7 hari $\times 7,6 \mathrm{~m}$ & $53,2 \mathrm{~m}$ \\
3 & Benang Jahit & 7 hari $\times 181.570 \mathrm{~m}$ & $1.270 .990 \mathrm{~m}$ \\
4 & Benang Obras & 7 hari $\times 121.046,7 \mathrm{~m}$ & $847.326,9 \mathrm{~m}$ \\
\hline
\end{tabular}

Berdasarkan tabel 4 Lead Time dalam pemesanan bahan baku yang dilakukan oleh Jims Kaos adalah selama 7 hari. Untuk menghadapi ketidakpastian maka pada sistem persediaan ditetapkan persediaan darurat yang dinamakan safety stock. Safety Stock dapat dilihat dari Lead Time x kebutuhan bahan per hari.

Reorder Point dapat dihitung dengan kebutuhan Safety Stock ditambah kebutuhan Lead Time. Rincian reorder point bahan baku baju kaos pada Jims Kaos tahun 2017 nampak pada tabel 5.

Tabel 5. Rincian Reorder Point Bahan Baku Baju Kaos pada Jims Kaos Tahun 2017

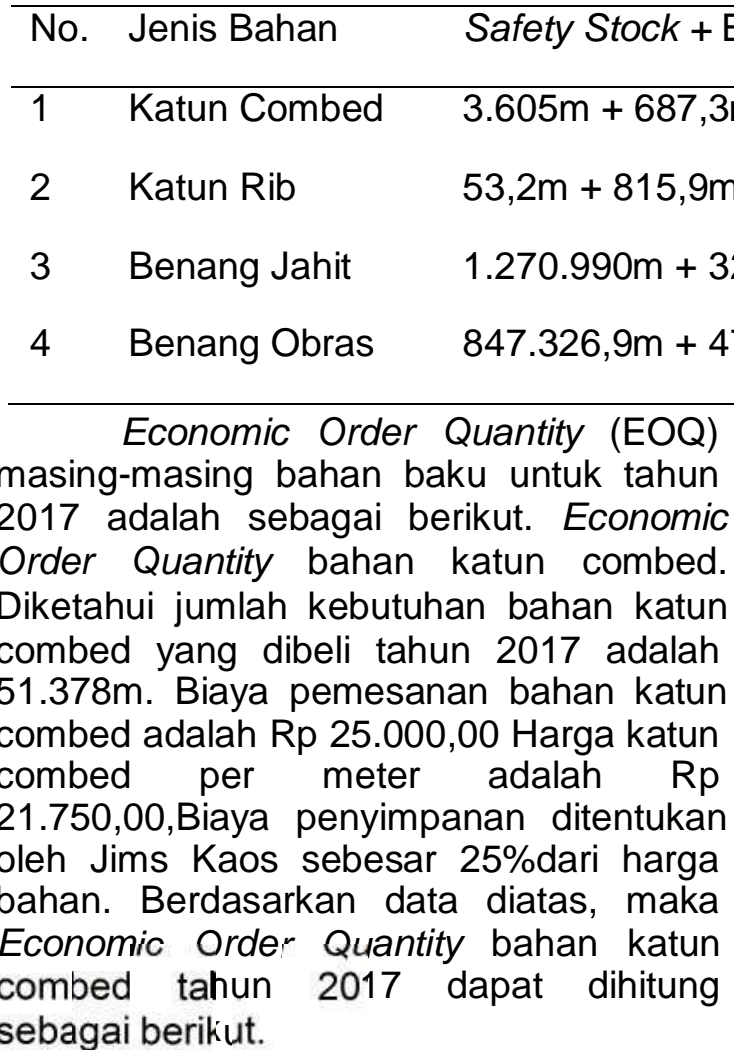

$Q=\sqrt{\frac{2 \times 25,000 \times 51 . .378}{n, 20} \times 21.750}$

$Q=\sqrt{\frac{50: 000 \times 51: 378}{5.4275}}$

$Q=\sqrt{\frac{2: 5^{68.900 .000}}{5.437,5}}$
Persediaan Maksimum

$4.292,3 m$

$869.1 \mathrm{~m}$

$1.303 .792 m$

89 $4.800,2 m$

$$
\begin{aligned}
& Q=\sqrt{472.441,37931} \\
& Q=687.3 \mathrm{~m}
\end{aligned}
$$
Jadi Economic Order Quantity atau jumlah pembelian yang paling ekonomis untuk bahan katun combed tahun 2017 adalah sebesar $687,3 \mathrm{~m}$. Economic Order Quantity bahan katun rib.Diketahui jumlah kebutuhan bahan katun rib yang dibeli tahun 2017 adalah 2.237,2m. Biaya pemesanan bahan katun rib adalah $\mathrm{Rp}$ 22.000,00. Harga katun rib per meter adalah $\mathrm{Rp} R p \quad 6.000,00$. Biaya penyimpanan ditentukan oleh Jims Kaos sebesar 25\%dari harga bahan. Berdasarkan data diatas, maka Economic Order Quantity: bahan katun rib tahun 2017 dapat dihitung sebagai berikut.

$$
\begin{aligned}
& Q=\sqrt{\frac{2 \times 22,000 \times 2.237,2}{n, 75 \times 6: 0^{n} n}} \\
& Q=\sqrt{\frac{44: 000 \times 2: 2^{37,2}}{1.500}}
\end{aligned}
$$


p-ISSN : 2599-1418

$e^{\operatorname{lnn} \cdot-599-1426}$

$Q=\sqrt{\frac{998: 436.800}{1.500}}$

$Q=\sqrt{665^{624,53333}}$

$Q=815.9^{\mathrm{m}}$

Jadi Economic Order Quantity atau jumlah pembelian yang paling ekonomis untuk bahan katun ribtahun 2017 adalah sebesar $815,9 \mathrm{~m}$.

Economic Order Quantity bahan benang jahit Diketahui jumlah kebutuhan bahan benang yang dibeli tahun 2017 adalah 66.590.190m Biaya pemesanan bahan benang jahit adalah Rp 12.000,00 Harga benang jahit per gulung adalah Rp 594,00 Biaya penyimpanan ditentukan oleh Jims Kaos sebesar 25\%dari harga bahan. Berdasarkan data diatas, maka Economic Order Quantity bahan benang jahit tahun 2017 dapat dihitung sebagai berikut.

$Q=\sqrt{\frac{2 \times 12.100 \times 66 \mathrm{c}}{1,25 \times 594}}$

$Q=\sqrt{\frac{24 . \quad x 66590.190}{0,48^{\mathrm{c}} 4}}$

$Q=\sqrt{\frac{1.5 .000 \quad .590 .190}{, 5}}$

$Q=\sqrt{1.078 .164 .560 .000}$

$\mathrm{Q}=32.80, \quad 148,5$

$=1.076 .205 .090,9$

$\mathrm{Q}=32.805,6$

Jadi Economic Order Quantity atau jumlah pembelian yang paling ekonomis untuk
Jurnal Pendidikan Ekonomi Undiksha

Volume 10 No. 1 Tahun 2018

bahan benang jahit tahun 2017 adalah sebesar 32.805,6m

Economic Order Quantity bahan

benang obras. Diketahui jumlah kebutuhan bahan benang obras yang dibeli tahun 2017 adalah 44.373.376,9m. Biaya pemesanan bahan benang obras adalah $\mathrm{Rp} 32.000,00$. Harga benang obras per gulung adalah Rp 504,00. Biaya penyimpanan ditentukan oleh Jims Kaos sebesar 25\%dari harga bahan.. Berdasarkan data diatas, maka Economic Order Quantity bahan benang obras tahun 2017 dapat dihitung sebagai berikut.

$$
\begin{aligned}
Q & =\sqrt{\frac{2 \times 32.10 \hat{0} . Q 44.37}{0,25 \times 504}} \\
Q & =\sqrt{\frac{64 . \quad x 443.376,9}{12 \rho, 2}} \\
Q & =\sqrt{\frac{283 .}{.000 \quad .373 .376,9}} \\
Q & =\sqrt{2.25} \\
Q & =47.47 \\
& =\quad 283.992 .121 .600 \\
Q & =2253.905 .726,98 \\
& 47.473,3
\end{aligned}
$$

Jadi Economic Order Quantity atau jumlah pembelian yang paling ekonomis untuk bahan benang obras tahun 2017 adalah sebesar $47.473,3 \mathrm{~m}$.

Rincian Economic Order Quantitybahan baku baju kaos pada Jims Kaos tahun 2017 nampak pada tabel 6

Tabel 6 Rincian Economic Order QuantityBahan Baku Baju Kaos Pada Jims Kaos Tahun 2017

\begin{tabular}{lll}
\hline No. & \multicolumn{1}{c}{ Jenis Bahan } & Jumlah \\
\hline 1 & Katun Combed & $687,3 \mathrm{~m}$ \\
2 & Katun Rib & $815,9 \mathrm{~m}$ \\
3 & Benang Jahit & $32.805,6 \mathrm{~m}$ \\
4 & Benang Obras & $47.473,3 \mathrm{~m}$ \\
\hline
\end{tabular}


p-ISSN : 2599-1418

e-ISSN : 2599-1426

\section{Pembahasan}

Berdasarkan hasil perhitungan mengenai perencanaan dan pengendalian persediaan bahan baku baju kaos tahun 2017 maka perencanaan dan pengendalian yang dapat dilakukan dengan menyusun rencana penjualan, menyusun rencana produksi, menyusun rencana kebutuhan bahan baku, menyusun rencana pembelian bahan baku maka pemilik perusahaan dapat menentukan perencanaan persediaan bahan baku tersebu. Hal ini sejalan dengan pendapat yang di kemukakan oleh Pardede (2005) secara umum perencanaan dalam kebutuhan persediaan bahan baku mencakup seluruh kegiatan mulai dari penentuan jumlah dan jenis bahan baku yang dibutuhkan, pencararian sumber dan tempat memperolehnya, cara pembeliannya dan ketempat produksi. Perencanaan bahan baku merupakan salah satu faktor yang menjamin kelancaran proses produksi pada wakti yang akan datang.

Pengendalian persediaan bahan baku baju kaos tahun 2017 Jims Kaos sebaiknya menyediakan persediaan minimum (safety stock) pada masingmasing bahan baku. Sehingga dengan adanya perhitungan menentukan persediaan minimum (safety stock), menentukan reorder point, dan menentukan persediaan maksimum maka pemilik perusahaan dapat menentukan pengendalian persediaan bahan baku tersebut. Hal ini sejalan dengan pendapat yang dikemukanan oleh Indrajit \& Djokopranoto (2003) Pengendalian persediaan merupakan kegiatan yang berhubungan dengan perencanaan, pelaksanaan, dan pengawasan penentuan kebutuhan material sebagian rupa sehingga disatu pihak kebutuhan operasi dapat dipenuhi pada waktunya dan dilain pihak investasi persediaan material dapat ditekan secara optimal.

Berdasarkan hasil perhitungan dengan menggunakan metode Economic Order Quantity (EOQ) tahun 2017 dapat membantu Jims Kaos dalam menentukan jumlah pembelian bahan baku yang paling optimal serta dapat meminimalkan biaya per periode. Sejalan dengan pendapat
Jurnal Pendidikan Ekonomi Undiksha

Volume 10 No. 1 Tahun 2018

yang dikemukakan oleh Martono (2008:84) "Economic Order Quantity (EOQ) adalah jumlah bahan baku yang dibeli dengan biaya persediaan yang minimal atau sering disebut jumlah pesanan bahan yang optimal".

\section{SIMPULAN DAN SARAN Simpulan}

Berdasarkan hasil pembahasan yang telah diuraikan maka dapat dibuat simpulan sebagai berikut. Rencana penjualan baju kaos pada Jims Kaos tahun 2017 sebesar 38.803 baju.

Rencana produksi baju kaos pada Jims Kaos tahun 2017 sebesar36. 314 baju.Kebutuhan bahan baku baju kaos pada Jims Kaos tahun 2017 sebagai berikut kebutuhan bahan katun combed tahun 2017 sebesar $54.471 \mathrm{~m}$, kebutuhan bahan katun rib tahun 2017 sebesar $2.724 \mathrm{~m}$, kebutuhan bahan benang jahit tahun 2017 sebesar 65.365.200m, kebutuhan bahan benang obras tahun 2017 sebesar $43.576 .800 \mathrm{~m}$. Pembelian bahan baku baju kaos pada Jims Kaos tahun 2017 antara lain: pembelian bahan katun combed tahun 2017 sebesar $51.378 \mathrm{~m}$, pembelian bahan katun rib tahun 2017 sebesar 2.237,2m, pembelian bahan benang jahit tahun 2017 sebesar 66.590.190m, dan pembelian bahan benang obras tahun 2017 sebesar 44.373.376,9m.Persediaan minimum (safety stock) bahan baku baju kaos pada Jims Kaos tahun 2017 anatara lain: persediaan bahan katun combed sebesar $3.605 \mathrm{~m}$, persediaan bahan katun rib sebesar $53,2 \mathrm{~m}$, persediaan bahan benang jahit sebesar 1.270.990m, dan persediaan bahan benang obras sebesar 847.326,9m. Reorder Point bahan baku baju kaos pada Jims Kaos pada tahun 2017 adalah 14 hari.Persediaan maksimum bahan baku baju kaos pada Jims Kaos tahun 2017 sebagai berikut persediaan maksimum bahan katun combed sebesar $4.292,3 \mathrm{~m}$, persediaan maksimum bahan katun rib sebesar $869,1 \mathrm{~m}$, persediaan maksimum bahan benang jahit sebesar $1.303 .792 \mathrm{~m}$, dan persediaan maksimum bahan benangg obras sebesar 894.800,2m. Economic Order Quantity (EOQ) bahan baku baju 
p-ISSN : 2599-1418

e-ISSN : 2599-1426

kaos pada Jims Kaos tahun 2017 antara lain: bahan katun combed sebesar $687,3 \mathrm{~m}$, bahan katun rib sebesar $815,9 \mathrm{~m}$, bahan benang jahit sebesar $32.805,6 \mathrm{~m}$, dan bahan benang obras sebesar 47.473,3m.

\section{Saran}

Berdasarkan simpulan di atas,
adapun saran-saran yang dapat
digunakan oleh pihak perusahaan dalam
menetapkan kebijakan terutama dalam
perencanaan dan pengendalian persediaan bahan baku di masa yang akan datang. Sebaiknya Jims Kaos membuat perencanaan dan pengendalian persediaan bahan baku setiap tahunny. Hal tersebut bertujuan agar Jims Kaos dapat merencanakan jumlah persediaan yang seharusnya ada pada tahun tersebut serta mengendalikan jumlahnya menggunakan perhitungan yang ada. Jims Kaos sebaiknya meningkatkan kerjasama dengan pihak supplier bahan baku agar bahan baku yang dibutuhkan selalu dapat dipenuhi.

\section{DAFTAR PUSTAKA}

Assauri, Sofjan. 2004. Manajemen Pemasaran. Jakarta: Rajawali Press.

Handoko, T.Hani. 2000. Dasar-Dasar Manajemen Produksi dan Operasi. Yogyakarta: BPFE.

Hansen \& Women. 2011. Akuntansi Manajerial. Edisi 8 Buku 1 terjemahan. Jakarta: Selemba Empat.

Indrajit \& Djokopranoto. 2003. Manajemen Persediaan. Jakarta: PT Gramedia Widiasrana Indonesia.

Kasmir. 2010. Pengantar Manajemen Keuangan, Jakarta: prenadamedia Group.

Martono \& D. Agus Harjito. 2008. Manajemen Keuangan. Cetakan Ke-7. Ypgyakarta: Ekonesia

Pardede, Ponts M. 2005. Manajemen Operasi dan Produksi: Teori,
Jurnal Pendidikan Ekonomi Undiksha

Volume 10 No. 1 Tahun 2018

Model dan Kebijakan. Yogyakarta: Andi.

Rangkuti, Freddy. 2000. Manajemen Persediaan: Aplikasi di Bidang Bisnis. Cetakan Ke-4. Jakarta: PT Raja Grafindo Persada

Slamet Sugiri. 2009. Akuntansi Pengantar 2. Edisi Kelima. Yogjakrta: UPP STIM YKPN

Strong P. Earl. 2003. Manajemen: Dasar, Pengertian, dan Masalah. Edisi Revisi. Jakarta: PT Bumi Aksara

Sumayang, Lalu. 2003. Dasar-Dasar Manajemen Produksi \& Operasi. Jakarta: Salemba Empat

Terry, George R dan Leslie W.Rue. 2008. Dasar-Dasar Manajemen. Terjemahan G.A. Ticoalu. Principles of Management. 1992. Jakarta: PT Bumi Aksara

Witjaksono, Armanto. 2013. Akuntansi Biaya. Edisi Revisi Cetakan Pertama. Yogyakarta: Graha IImu 